\title{
Legislatures, Courts, and Statutory Control of the Bureaucracy across the U.S. States*
}

\author{
Robert J. McGrath ${ }^{\dagger}$ \\ $<$ rmcgrat2@gmu.edu $>$
}

February 6, 2012

*Paper prepared for presentation at the 12th Annual State Politics and Policy Conference, Houston, TX, February 18, 2012. Comments welcome. I would like to thank Chuck Shipan for access to his and John Huber's data, which was essential for this paper. Please do not cite or circulate without permission.

$\dagger$ Assistant Professor, Department of Public and International Affairs, George Mason University, Fairfax, VA 22030 


\begin{abstract}
How do state legislatures use statutory language to control policy implementation by state agencies? In this paper, I consider the extent to which the decision of how best to control bureaucratic policymaking is strategic in regards to the broader political context in which a legislature finds itself. Specifically, I examine the extent to which legislatures anticipate the likely actions of state courts in crafting their policymaking directives to bureaucrats in a specific policy area and time period. Previous literature (e.g., Huber, Shipan and Pfahler (2001)) has argued that the legislative use of statutory language to control bureaucrats varies with the availability of nonstatutory methods of control, but it does not explicitly consider the role of state courts. My hypotheses are derived from a simple formal model of executive-legislative relations and my expectations are such that the degree of statutory control should increase only when a state legislature's preferences are sufficiently different from the executive's and when nonstatutory controls, i.e., the extent to which state supreme courts are likely to overturn agency action, in that state are neither too high nor too low. This counterintuitive expectation is supported when I test hypotheses using the original Huber, Shipan and Pfahler (2001) data on the number of words added to a state's Medicaid laws from 1995-1996. These findings are important in that they support a general model of legislative policymaking and elucidate the importance of state-specific capacities in shaping executive-legislative relations at the subnational level.
\end{abstract}


Literature in public administration and political science has long recognized that unelected bureaucratic agencies can significantly affect federal policymaking. For example, the cultivation of a reputation for neutral expertise can allow federal agencies, such as the USDA, FDA, and OSHA (Carpenter, 2001, 2010; Huber, 2007), to autonomously determine the contours of federal policy within jurisdictional limits. Even when agencies cannot directly affect the legislative content of policy in this way, much research (Epstein and O'Halloran, 1999; Huber and Shipan, 2002, e.g.,) has confirmed that political principals often have an incentive to delegate policymaking authority to the bureaucracy. Students of state politics are beginning to take notice of bureaucratic policymaking and to assess the extent to which these characteristics of legislative-executive relations hold at the subnational level. As the roles of state bureaucracies have become more important, the field has paid closer attention to the conditions, theorized at the federal level, under which they can affect policy (Potoski, 1999; Teske, 2004; Kim and Gerber, 2005; Poggione and Reenock, 2009).

In a forthcoming chapter on policy delegation across the states, Krause and Woods (2012) review recent literature on the subject and conclude that in order to better understand bureaucratic politics at the subnational level, scholars should begin with truly comparative state-level theories, rather than simply applying those theories generated at the national level. The key weakness in exporting these theories is that they do not adequately account for variations in relevant capacities. In particular, Krause and Woods (2012) seek to build a framework centered on the relative institutional capacities of the state legislatures, governors, and bureaucracies. At a fundamental level, the current paper joins Krause and Woods's attempt to provide an institutional explanation for the diversity of executive-legislative relationships that we observe across the U.S. states. In particular, I assess the institutional determinants of the amount of statutory discretion that state legislatures delegate to state agencies. The theoretical approach holds that variation in both legislative capacity and the likelihood of exogenous ex post monitoring by the courts should condition the legislature's strategic delegation of policymaking authority. In so doing, I add state judicial branches to Krause and Woods's matrix of state-level institutional variables to consider in studying subnational policy delegation. 
The key contribution of this paper is a demonstration that state legislatures impose statutory language meant to limit agency discretion according to the unique pattern predicted by the policymaking model presented herein. I reanalyze Huber and Shipan (2002)'s data on statutory discretion in Medicaid policy across 48 states in 1995-1996 and find that legislatures likely anticipate the actions of state courts when they craft their policymaking strategies. This is an important contribution because it adds an additional "separation of powers" nuance (de Figueiredo Jr., Jacobi and Weingast, 2008) to the extant literature on substitution effects between ex ante and ex post strategies (Bawn, 1997; Huber, Shipan and Pfahler, 2001; Huber and Shipan, 2002; Gailmard, 2002). To preview the main insight of this paper, I demonstrate that state court activism, as a form of nonlegislative, nonstatutory policy control is, as expected, nonlinearly related to statutory control, with the latter increasing when state court activism is neither too high nor too low.

In the next section, I briefly review the literature on the institutional design of bureaucratic agencies, focusing specifically on the conditions under which legislatures delegate policy authority to agencies. I then derive unique nonlinear predictions from a general model of legislative policymaking and formulate empirical hypotheses, with an emphasis on the mechanism by which I expect nonlegislative, nonstatutory factors, such as the activism of state courts, to affect statutory discretion across states. Next, I operationalize the key theoretical variables and construct the appropriate nonlinear empirical models to test these expectations, including the specification of a number of nonparametric Generalized Additive Models (GAM). The fourth section presents the results of the different model specifications, demonstrating broad support for the insights of the theoretical model, and the final section concludes with a discussion of contributions, shortcomings, and implications for future work.

\section{Variation in Legislative Policymaking Strategies}

According to Black's Law Dictionary, discretion (in this sense) is “4. A public official's power or right to act in certain circumstances according to personal judgement and conscience, often in 
an official or representative capacity" (Garner, 2006). Especially when considering the "representative" nature of this definition, it is intuitive to consider this power to be constitutionally in the purview of legislatures in separation of powers systems. Indeed, under a strict separation of powers interpretation of the Constitution of the United States, delegation of discretion from Congress to executive agencies is to be avoided unless "Congress prescribes an intelligible principle to guide an executive agency in making policy" (Garner, 2006, p.362), which is to say that Congress can only delegate when they do so without granting much or any discretion. In constitutional law, this is known as the non-delegation doctrine ${ }^{1}$, but the practical realities of modern government lead this principle to be mostly ignored. Legislatures (Congress and U.S. state legislatures) do in fact give great discretion to administrative agencies to implement policy that may or may not reflect the will of the legislature. The structure of this problem is precisely what makes it amenable to the principal-agent approach taken in this paper.

This general approach is not foreign to the study of executive-legislative relations. Contesting claims that legislative grants of administrative discretion implied administrative dominance (and concomitant legislative impotency) (McConnell, 1966; Lowi, 1969; Niskanen, 1971; Offe, 1972; Putnam, 1975; O’Connor, 1978; Peters, 1981; Aranson, Gellhorn and Robinson, 1982; Rourke, 1984), McCubbins and Schwartz (1984), and McCubbins, Noll and Weingast (1987, 1989) argued that legislators, as the principals, can alter bureaucratic incentives with statutory language. That is, although legislators need to delegate, they can maintain some degree of control over what their administrative agents do with their delegated discretion. This literature draws on descriptive accounts of the federal Administrative Procedures Act of 1946 (Davis, 1978; Shapiro, 1982; Bonfield, 1986; Gellhorn, 1986) to argue that procedural requirements (stipulated in APAs or in individual statutes) can help to reign in potentially discretion-abusing bureaucrats through the "politics of structural choice" (Moe, 1990). In addition to procedural limits on discretion, scholars have proposed that legislators can limit discretion more directly, by controlling the specificity of the legislation meant

\footnotetext{
1“The principle (based on the separation-of-powers concept) limiting Congress's ability to transfer its legislative power to another governmental branch, esp. the executive branch" (Garner, 2006, p.362).
} 
to delegate authority to bureaucrats (Epstein and O'Halloran, 1994, 1996, 1999; Huber, Shipan and Pfahler, 2001; Huber and Shipan, 2002). ${ }^{2}$ Huber and Shipan (2002) introduce this idea of "statutes as blueprints for policymaking" by positing that:

When legislative statutes are specific, they make it more difficult for other political actors, especially bureaucrats, to enact policies that differ from those that legislative majorities prefer. Thus, specific statutes allow legislative majorities to limit the policymaking discretion of other political actors, while vague statutes give a larger policymaking role to these other actors (p. 44).

Considering the analogy of a blueprint, by including more specific prescriptive language into statutes, legislators make implementation of the policy program included in that statute straightforward. When there are fewer specific steps for bureaucrats to follow in implementing a statute, it is natural that they can more readily consider their own "personal judgement and conscience;" that is, their own discretion. Taking these two types of ex ante strictures on discretion together (procedural and statutory), de Figueiredo Jr., Jacobi and Weingast (2008) discuss a potential "separation of powers" confounding factor that I further explore in the next section:

By introducing strict limits of discretion, administrative procedures ensure that outcomes will be closer to an elected official's ideal than if the agency had an unlimited range of options. But the mechanism only works if there is ex post enforcement of the rules... If the courts ruled consistently with the intent of Congress, then the bureau would have strong incentives to follow their intent. On the other hand, by implication, if the courts were not aligned with the legislature, such mechanisms would provide the bureau with more latitude to implement policy (p. 214).

Where the structure of my approach is similar to the literature reviewed here, the implications of the model explicated in the next section are unique precisely because I consider the extent to which ex

\footnotetext{
${ }^{2}$ I say that a prescriptive limiting of statutory discretion is more direct than procedural arrangements because they are more specific in nature and the policy outcomes are more certain to legislators. In addition, empirical research has demonstrated that procedural arrangements may be largely ineffectual (Balla, 1998; Hamilton and Schroeder, 1994).
} 
post capacity (through, say, oversight hearings) manages to enforce the limits of ex ante discretion in the context of such extra-legislative and extra-executive policymakers such as state courts. Put simply, my approach is comprehensive in that it incorporates the insights of the works reviewed below in a theoretically synthetic way. Before I translate the theoretical insights into specific empirical hypotheses and test them in succeeding sections, I first delineate some alternative or complementary explanations for levels of statutory discretion from the literature.

Previous literature suggests that legislators vary levels of bureaucratic discretion in accordance with intra- and inter- institutional variation. At the inter-institutional level, a host of scholars have argued that legislators consider the extent to which their policy preferences diverge from the bureaucratic agents' to whom they wish to delegate (Epstein and O'Halloran, 1999; Potoski, 1999; Huber, Shipan and Pfahler, 2001; Huber and Shipan, 2002; Lewis, 2003; Wood and Bohte, 2004). In the context of principal-agent theory, this is an entirely plausible explanation for why some legislators at some times write more or less restrictive legislation than others. Legislators simply trust like-minded policy-implementers more than those with starkly different preferences from them and, assuming that restricting discretion with statutory language is costly, seek to minimize their transaction costs without too much policy loss.

In addition to this preference-based story, Bawn (1995), Epstein and O'Halloran (1999), and Huber and Shipan (2002) argue that the cost of restricting discretion can increase with the complexity of a policy area. As a corollary then, their arguments imply that variation in statutory discretion across legislatures can be partially attributed to variations in legislative capacity to deal with (i.e., their ability to design policy that achieves their preferred outcomes) technically/scientifically complex policy areas. A second important intra-institutional potential explanation for a legislature's willingness to limit an agency's discretion is the extent to which they can rely on alternative, and potentially less costly, means to control bureaucratic decisionmaking. A central insight of Huber, Shipan and Pfahler (2001) and Huber and Shipan (2002) is that as legislatures become better able to control policy ex post (say, through oversight activities), they have fewer incentives to incur the costs of ex ante restrictions on discretion. However, this literature does not go beyond this sim- 
ple substitution calculus and fails to explicitly consider the extent to which external institutional actors, like the courts (de Figueiredo Jr., Jacobi and Weingast, 2008), can affect this decision.

Building on this research and that on the origins of bureaucratic autonomy (Carpenter, 2001) and agency termination (Carpenter, 2000; Carpenter and Lewis, 2004), MacDonald and Franko (2007) argue that discretion is also related to bureaucratic capacity, with better performing agencies receiving more freedom to implement policy as they see fit than do agencies with less capacity. However, instead of examining the extent to which Congress restricts an agency's discretion with prescriptive language, these authors analyze the proclivity of Congress to attach limitation riders to agency appropriations. These statutory provisions can preclude agencies from exercising discretion in that they circumscribe the types of things for which the agency can spend its appropriations. ${ }^{3}$ Although these riders are included in appropriations statutes, they are less an ex ante mechanism of control than they are decided ex post, that is, after an agency makes a policy implementation decision. The tool itself, like procedural requirements, exists as an ex ante threat, but the way that MacDonald (2010) conceptualizes its implementation is as an after-the-fact punishment for recalcitrant bureaucrats. Still, the observation that these instruments are used to statutorily proscribe agency action is relevant to my endeavor here. Although I do not assess data on the use of limitation riders across the states, I discuss, in the conclusion, ways to incorporate MacDonald (2010)'s and MacDonald and Franko (2007)'s contributions into the framework of this analysis.

As much of this literature (with the important exceptions of Huber, Shipan and Pfahler (2001) and Huber and Shipan (2002)) focuses on the relationship between Congress and the federal bureaucracy, it may miss important mediating effects of cross-institutional variation (Huber, Shipan and Pfahler, 2001; Krause and Woods, 2012). Besides these studies, there has not been much literature on cross-state empirical assessments of statutory discretion. In fact, there is a dearth of empirical legislative-executive relation studies at the state level in general. What we do know is

\footnotetext{
${ }^{3}$ MacDonald and Franko (2007, p. 795) provide the following example of a limitation rider: “ ... the fiscal year 2001 Labor, Health and Human Services, and Education appropriations bill mandated that 'none of the funds ... may not be used by the Occupational Safety and Health Administration to promulgate, issue, implement, administer, or enforce any proposed, temporary, or final standard on ergonomic protection.' "
} 
that legislative capacity varies across the states and this has predictable effects on legislative control of state bureaucracies (Elling, 1979; Hamm and Robertson, 1981; Potoski and Woods, 2000; Woods and Baranowski, 2006) and that institutional change, such as the imposition of legislative term limits (Berman, 2004; Carey, Niemi and Powell, 2000; Carey et al., 2006; Farmer and Little, 2004; Kousser, 2005; Kurtz, Cain and Niemi, 2007; Sarbaugh-Thompson et al., 2010), can potentially change the nature of state legislative-executive relationships. The current research adds to this literature by incorporating insights from a cross-institutional theory of statutory control of bureaucracy into a cross-sectional empirical model at the level of the U.S. states.

\section{A Theory of Strategic Delegation and Oversight}

The theoretical model from which I derive the empirical expectations tested in this paper is influenced by the delegation models in Huber and Shipan (2002). This work emphasizes the importance of statutory means for controlling bureaucratic action. Legislators write laws that delegate variably broad authority to bureaucrats. If they want to more closely control bureaucratic behavior, they can write more detailed legislation, thus constricting the scope of an agency's discretion. However, this literature has established that constricting bureaucratic discretion can sometimes be superfluous; that is if legislators think that bureaucrats, acting with their own self-interest in mind, will implement policies in line with the preferences of the legislators. In such a context of complete delegation, oversight may be an even more essential tool for legislators than it would be if they had delegated less discretion. Under different conditions, though, oversight may be just as superfluous as statutory constraints on agency action. In order to determine whether this is the case and to establish the conditions, I consider both ex ante (delegation of statutory discretion) and ex post (legislative oversight) mechanisms of control simultaneously in this analytical model. The full treatment of the model can be found in McGrath (2011) (http://mason.gmu.edu/ rmcgrat2/GMU/research), but I will briefly summarize the logic of the empirical predictions it yields.

As is standard in principal-agent models of legislative policy control, I make a number of simpli- 
fying assumptions to keep the model tractable and yield testable hypotheses. There are two types of players, "Legislators" and "Bureaucrats." The Legislator is considered to be a pivotal legislator in a legislature or committee and the Bureaucrat a key decision-maker in an executive agency. Quite simply, Legislators design policy, which the Bureaucrats implement, resulting in policy outcomes. I assume that both players care solely about policy outcomes, but that Bureaucrats are always better informed about the mapping of policy to policy outcomes. This idea is captured by the fact that Bureaucrats always know how to achieve any policy outcome, but Legislators only know this with some probability. Legislators and Bureaucrats need not have the same policy preferences, but they may.

I assume that writing statutes is costly for the Legislator and that the cost increases as the capacity of the Legislator to write detailed laws decreases and as the extent to which these laws are specific increases. I also assume that it is costly for a Legislator to investigate a Bureaucrat if she thinks that the Bureaucrat has acted illegally (i.e., outside of the bounds of discretion). This cost is also increasing with the extent to which the Legislator is generally unable to write detailed laws. In order to keep the model simple, I use one variable ( $a$ ) for both types of legislative capacity. Bureaucrats are not literally bound by delegated limits on discretion and may or may not choose to implement the policy chosen by the Legislator. Nevertheless, acting in a way that the Legislator disapproves of can lead to an investigation (i.e., an oversight hearing), which will be costly to the Bureaucrat. I assume that both players have linear spatial utilities and that the Legislator has an ideal point, $x_{L}=0$, and that the Bureaucrat has an ideal point at some $x_{B} \geq 0$.

In general, the sequence is simple and space constrains inclusion of many of the details here, so I will briefly outline how the game is played out. First, Nature ${ }^{4}$ determines a policy shock. Either the policy outcome will equal what B (the Bureaucrat) implements or the outcome will shift one unit to the left of where it is implemented. Again, B knows the value of this shock, but L (the Legislator) can only use the B's behavior to infer its value. The first strategic action is taken by $\mathrm{L}$ who writes a law delegating an amount of policymaking discretion to B. L takes into account how costly it is

\footnotetext{
${ }^{4}$ This is a standard way of introducing uncertainty and informational asymmetry into the structure of the model.
} 
to write the law and her expectations that more restrictive (and costly) laws could constrain B's behavior in ways favorable to L. Next, B implements a policy, be it either legal or illegal (i.e., outside of the bounds of discretion set in the previous stage). Finally, L observes which policy B implements and can choose to investigate (hold an oversight hearing) or not. If she investigates, with cost $a$, then the outcome goes to her ideal point, but if she does not, the outcome is what B implements with or without the policy shock. If L investigates and B has acted illegally, B must also pay a cost, so he prefers to not be investigated. As the rounds of play are completed, there is an exogenous chance that some nonstatutory, nonoversight mechanism benefits L and reverts the outcome to her ideal point. This is an important factor in the technical solution to the model and produces the implications for the role of courts in the policymaking process as examined below (see McGrath (2011) for more details).

Having introduced the model in broad strokes, I will now characterize the equilibrium outcomes that lead to hypotheses concerning the delegation of policymaking discretion from a legislature to an agency. My strategy for characterizing the equilibria is to do so in terms of B's position relative to L and the other parameters in the model (denoted by the term "region" below). Generally, these results predict that $\mathrm{L}$ only restricts discretion ex ante under certain values of the probability (call this $\gamma$ ) of exogenous reversion from the final stage of the game. These results also predict that L (state legislatures) conduct oversight hearings endogenously to enforce the limits of delegated authority. Importantly, there are conditions under which L would prefer to rely solely on these ex post methods of control, and conditions under which L would use ex post and ex ante control as complementary strategies. For the current paper, I focus on the predictions broadly concerning the types $^{5}$ of laws state legislators write in specific policy domains.

First, where $x_{B}<a$ (Figure 1) or $a \leq x_{B} \leq a+\frac{1}{2}$ (Figure 2), L neither limits discretion in a statute, nor conducts oversight hearings. The effects of these tools of control can be seen in Region 2 ( $a \leq x_{B} \leq a+\frac{1}{2}$ ), where $\mathrm{B}$ moderates his policy choice in light of the oversight

\footnotetext{
${ }^{5}$ The empirical analyses here focus on the prescriptive length and specificity of these laws, but I conclude by discussing ways to examine further characteristics (procedural requirements, limitation riders, etc.) of these laws in future research.
} 
threat, but the model predicts that neither will be used when B is sufficiently close to L. These two preference-determined regions denote situations where legislative and bureaucratic preferences are close enough to consider the two policymaking branches ideological allies. In these situations, the outcomes from the model conform to intuition: principals need not work very hard to control agents who want the same outcomes they do. Taken together, these equilibria lead to this formulation of related empirical hypotheses:

Hypothesis 1a: When ideological conflict between an executive agency and a state legislature is sufficiently low $\left(x_{B} \leq a+\frac{1}{2}\right)$, changes in neither ideological conflict, legislative expertise, nor the probability of the courts affecting policy in the legislature's favor should lead to changes in the extent to which the legislature limits the agency's statutory discretion.

Relatedly,

Hypothesis 1b: When the cost of limiting an agency's discretion is sufficiently high $\left(a \geq x_{B}-\frac{1}{2}\right)$, changes in neither ideological conflict, legislative expertise, nor the probability of the courts affecting policy in the legislature's favor should lead to changes in the extent to which the legislature limits the agency's statutory discretion.

When $x_{B}$ becomes too large relative to $a\left(x_{B}>a+\frac{1}{2}\right.$, Figure 3$)$, legislators and bureaucrats can no longer be considered ideological allies and oversight will occur with positive probability, but this does not guarantee that L will limit the agency's discretion as a complementary strategy. In fact, in this model, variation in the theoretical variables $x_{B}$ and $a$ never lead to changes (independent of the value of $\gamma$ ) in the extent to which L is willing to pay the cost of limiting B's discretion. However, for the case where $x_{B}$ is in Region $3\left(x_{B}>a+\frac{1}{2}\right)$, when $\gamma$ is either sufficiently low $\left(\gamma<-\frac{-x_{B}+a}{x_{B}(a+1)}\right)$ or sufficiently high $\left(\gamma>\frac{1}{a+1}\right)$, L does not limit discretion ex ante, but does conduct ex post investigations with a probability, $i=\frac{2 a+1-2 x_{B}}{a+1-2 x_{B}}$, that increases in $x_{B}$ and decreases in a. Here:

Hypothesis 2: When ideological conflict between an executive agency and a state legislature is sufficiently high $\left(x_{B}>a+\frac{1}{2}\right)$, or the cost of limiting an agency's discretion sufficiently low $(a<$ 
$\left.x_{B}-\frac{1}{2}\right)$, and $\gamma$ is either sufficiently low $\left(\gamma<-\frac{-x_{B}+a}{x_{B}(a+1)}\right)$ or sufficiently high $\left(\gamma>\frac{1}{a+1}\right)$, increases in neither ideological conflict, legislative expertise, nor the probability of the courts affecting policy in the legislature's favor should lead to changes in the extent to which the legislature limits the agency's statutory discretion.

However, when $x_{B}>a+\frac{1}{2}$ (Region 3) and $\gamma$ is neither sufficiently low nor sufficiently high $\left(-\frac{-x_{B}+a}{x_{B}(a+1)}<\gamma<\frac{1}{a+1}\right)$, L does limit discretion ex ante and conducts ex post investigations with a probability, $i=\frac{-2 x_{B}+2 a+2 \gamma a-2 \gamma x_{B}+\gamma d+1+\gamma}{-2 x_{B}-d+a+1+\gamma a+\gamma-2 \gamma x_{B}+\gamma d}$, that increases in $x_{B}$ and decreases in $a$. Therefore:

Hypothesis 3: When ideological conflict between an executive agency and a state legislature is sufficiently high $\left(x_{B}>a+\frac{1}{2}\right)$, or the cost of limiting and agency's discretion sufficiently low $\left(a<x_{B}-\frac{1}{2}\right)$, and $\gamma$ is neither sufficiently low nor sufficiently high $\left(-\frac{-x_{B}+a}{x_{B}(a+1)}<\gamma<\frac{1}{a+1}\right)$, state legislatures will be most likely to limit an agency's discretion ex ante with prescriptive statutory language.

In a previous paper (McGrath, 2010), I have assessed the model's predictions concerning levels of oversight hearings at the congressional level. This work confirms that neither $x_{B}$ nor $a$ have significant effects on the probability of oversight when $x_{B}$ is sufficiently low (Regions 1 and 2), but that both ideological distance between a congressional committee and an executive agency and the extent to which the committee has policy-specific expertise positively affect oversight in Region 3. In the current paper, I test the prediction that legislatures have the strongest incentive to limit discretion ex ante when they possess nonstatutory means of control $(\gamma)$ that are neither too high too low. Space and scope concerns have limited me to presenting a slightly disembodied theoretical account of what drives state legislatures to delegate discretion to agencies, but the intuition should be clear: legislatures respond to conditions where they expect the courts or some other non statutory mechanism to do their enforcement for them by expending as little cost as possible. Likewise, when they foresee an unsympathetic or restrained court, legislators have incentives to crack down on agencies with their own ex post enforcement measures. In contrast, it is when legislators are most unsure of the level of exogenous assistance from the courts that I predict they make the most effort to limit discretion ex ante, thereby relying on agencies to moderate their own implementation 
strategies in the face of punishment.

\section{Data and Methods}

The U.S. states provide the ideal context in which to test the expectations of the theory. First, as we will see, there is great variation in the extent to which state legislatures constrict agency action by limiting statutory discretion. Although it is true that congressional bills also vary in this regard, there exists no cross-sectional or regularly changing temporal variation in the institutional context of Congress. Most importantly for the analyses required here, it is difficult to operationalize the theoretical $\gamma$ term in a way that yields variation at the congressional level. Crucially, there are myriad ways to consider differences in the effectiveness of exogenous nonstatutory controls across the states.

Research by Huber, Shipan and Pfahler (2001) and Huber and Shipan (2002) similarly considers the effects of institutional variables on statutory discretion across the states. Therefore, I reassess the data ${ }^{6}$ used in these works in light of the expectations derived from the theory described above. Before I describe their independent variables and their expectations regarding them, I will describe the dependent variable and its measurement and explain how I choose to operationalize nonstatutory controls (the theoretical $\gamma$ ) across the states.

The dependent variable is the total number of new words that a state legislature put into law in the Medicaid (nonappropriations) policy area in 1995-96. When comparing statutory content, it is essential to control for issue area. A natural way to do that is to focus on a reasonably narrow issue that all states must deal with contemporaneously. Huber, Shipan and Pfahler (2001) and Huber and Shipan (2002) argue convincingly for the appropriateness of Medicaid data from this time period. Here is a description of the coding rule for the dependent variable:

We identified relevant legislation in each state by searching Lexis's “Advanced Leg-

\footnotetext{
${ }^{6}$ Acquired via personal correspondence with the authors.
} 
islative Service" database. ${ }^{7}$ For each state we used the search terms "Medicaid" and “medical assistance,' which are used interchangeably by states to refer to the Medicaid program, as well as any state-specific names for Medicaid programs (such as "Medical" in California or "MC+" in Missouri). We retained any nonappropriations bills that turned up in this search that were related to the provision of medical care for Medicaid participants. We then examined the content of the bill for relevance, and if it was only partially relevant (i.e., only partly about Medicaid health care) we edited out the irrelevant portions. We then used a macro in Microsoft Word to count all the words in the legislation that were new. This count of new words is the dependent variable, Statutory Control, that we focus on in our empirical tests (2001, p. 336)

These authors argue that the length of a statute, controlling for narrow policy area, is at least a proxy for the amount of statutory discretion given to a state health agency. The idea is that the longer a law is, the more detailed it should be in terms of instructing and directing (constricting) agency action. It certainly could be the case for a law to be relatively short in length, but full of discretion-limiting procedures. This hypothetical law certainly could be more restrictive than a much longer, but procedure-less law, but Huber and Shipan (2002) find that, at least for the sample they analyze, "procedures seem to play a minor role, relative to policy instructions, in all contexts" (p.72). ${ }^{8}$ Since I am using the same sample of data, I argue with Huber and Shipan (2002) for the appropriateness of statute length as a proxy for the amount of statutory control exercised by a legislature in this policy area.

Although the previous empirical research on the determinants of statutory discretion considers the effects of nonstatutory means of control, it usually does so with a indicator variable for the pres-

\footnotetext{
7 "We coded legislation for forty-eight states. We omitted Nebraska from the analysis because it has a unicameral legislature and our theory focuses on the difference between unified and divided legislatures. We omitted Virginia because in each year the state legislature would pass multiple copies of bills, each containing extremely similar (but not necessarily identical) language. Because of this redundancy, it was impossible to obtain even a reasonably accurate count of new words."

${ }^{8}$ See Huber and Shipan (2002, pp. 56-72) for a series of diagnostics showing the relatively scant use of procedural language in the state Medicaid statutes and demonstrating that, in any event, procedural restrictions tend to be correlated with statutory control.
} 
ence or absence of some extralegislative power. For example, Huber, Shipan and Pfahler (2001) and Huber and Shipan (2002) argue that the ability for state legislatures to veto administrative rules should mitigate their need to impose statutory constraints. Since I predict that statutory discretion depends on the probability that nonstatutory factors affect outcomes neither being too high nor too low, an indicator variable would be of little use to test the theory. I need to construct a continuous measure of nonstatutory factors that, since they influence policy outcomes, independent of ex ante legislative action, may reduce the incentive for legislators to write detailed statutes.

Decisions by the courts, especially concerning the appropriateness of administrative rules made by state agencies, affect policy outcomes well after laws have been written by legislatures. Therefore, the extent to which state courts may be favorable to legislative preferences should affect the initial delegation of discretion to state agencies. There exist no ready-made measures that capture both the extent to which state courts are favorable to legislatures and the extent to which they are activist in terms of overturning administrative actions. I have created an index that I believe captures these elements in a way appropriate for it to be a proxy for general nonstatutory controls $(\gamma)$

State Court Index is a measure that combines elements of state supreme court ideology and the extent to which each court overturns agency action, usually with the purported intent to further legislative will. A standard measure exists for the ideological preferences of state supreme court justices (Brace, Langer and Hall, 2000). This measure, the party-adjusted surrogate judge ideology measure (PAJID), is based primarily on a judge's partisan affiliation, the ideology of their state, and the manner in which they took office. Although policy-preferential and jurisprudential ideology are not synonymous, since the PAJID measure takes into account legislative preferences and not executive preferences, I use it as a proxy for the extent to which state supreme courts are willing to actively address (executive) governmental action. I aggregate this individual measure up to the supreme court level by taking the median PAJID score for each court in $1995 .^{9}$

\footnotetext{
${ }^{9}$ The PAJID measure is unbounded and takes on higher values with the extent to which a judge is determined to be liberal.
} 
To complete the index, I take the product of the state's median PAJID value for 1995 and the percentage of supreme court cases that involved an agency where the supreme court reversed agency action. These data are made available by the State Supreme Court Data Project, managed by Paul Brace and Melinda Gann Hall. ${ }^{10}$ This component of the measure captures judicial antagonism to agency action, which is an important variable given the concept of nonstatutory control. Since I hold that each component's effect on nonstatutory control depends on the level of the other, I multiplied the two measures together to create the index. So, very high values of State Court Index indicate a state where the supreme court is both very liberal and overturns agency action at a high rate, where very low values denote a very conservative and agency-friendly court. My expectations about State Court Index are parabolic, rather than linear, so multiplication of the component parts is a good way to capture the different dimensions of this kind of nonstatutory control without necessarily making ideological assumptions about, say, liberal judges being more likely to side with legislatures than with agencies. To review, my expectation is that Statutory Control, measured by the number of words added, should increase only when a legislature's preferences are sufficiently different from the executive's and when nonstatutory controls are neither too high nor too low. Table 1 contains descriptive statistics for this and other variables assessed in this paper.

I capture policy conflict ( $x_{B}$ from the theoretical model) rudimentarily with indicator variables for party control of institutions. Unified Legislature takes a value of 1 when a state governor's party controls neither legislative chamber. Similarly, the Divided Legislature variable takes the value of 1 when the governor's party controls one of the legislative chambers. Therefore, completely unified government is indicated when both of these variables take the value of 0 . Lacking better measures of state legislative and agency ideology, these variables are meant to capture the extent to which we can consider legislatures and executive agencies ideological allies or foes. Ideally, I would use more finely grained measures of policy conflict, but these require more intensive data collection and are planned for future work. Following the Huber, Shipan and Pfahler (2001) and Huber and Shipan (2002) convention, I operationalize legislative capacity (a) as the 1995 amount

\footnotetext{
${ }^{10}$ Available online at: http://www.ruf.rice.edu/ pbrace/statecourt/.
} 
of legislative Compensation — the annual salary plus per diem expenses for lower house members. Since it is reasonable to expect that the effects of capacity may diminish over the range, I performed all of the analyses with an untransformed Compensation term and a logged one. The results are substantively similar and I present coefficients for the the log-transformed variables in the analyses below.

As in the previous research, I model the interdependent effects of these important theoretical variables with multiplicative interaction terms. The natural log of Compensation is interacted with both Unified Legislature and Divided Legislature to capture the extent to which policy conflict may only become important when legislative capacity, with diminishing returns, is sufficiently high. Previous research has identified the legislative veto as an important nonstatutory factor that influences Statutory Control. Therefore, I include an interaction between a Legislative Veto indicator variable and Unified Legislature, with the idea that a unified legislature can wield this tool against a bureaucracy controlled by an opposition party governor, thereby lessening the need to control policy ex ante.

Including institutional interaction terms in cross-sectional studies at the state level eats up precious degrees of freedom. Therefore, I include only three true control variables in the models below. In the Huber and Shipan empirical work on statutory discretion, per capita Medicaid Expenditures is the only consistently important control variable. Inclusion of this variable should isolate statutory discretion from policy change by controlling for the size of a state's Medicaid program. I have estimated models using all of the control variables found in Huber, Shipan and Pfahler (2001), but these results are never substantively different from the more parsimonious models presented here. Due to their unique political history and the possibility that divided government means something different in southern states than it does in northern ones (Erikson, Wright and McIver, 1993), I include an indicator for the South. Finally, I include an indicator for California to control for that state's voluminous legislation, which has nearly three times more added words than the next largest amount.

I have good theoretical reason to expect that the effect of the primary independent variable, State 
Court Index, is nonlinearly related to the total number of new words added to state Medicaid policy. The theory I have explicated predicts that this relationship is discontinuous (i.e., there should be no effect for some values of State Court Index, and a positive effect for other values), but due to random error and other unmodeled determinants of Statutory Control, including the fact that there is no reason to believe the points of discontinuity across the states should be the same, this is unlikely to bear out perfectly. Therefore, it may be more reasonable to test whether there is at least a parabolic relationship between the variables. Among others, Keele (2008) warns against assuming linear specifications when we suspect that the true data-generating process implies a nonlinear relationship. As an alternative, in the next section I use nonparametric techniques to diagnose the expected nonlinearity from the data and semiparametric ones to model these appropriate functional forms.

\section{Results}

Figures 4 and 5 examine the functional form of the bivariate relationship between State Court Index and Statutory Control. Here, I use local weighted polynomial regression (lowess) to get a sense of the relationship between the two variables. Since local regression is nonparametric, there do not exist global summary parameters that allow us to assess the relationship with a single number or coefficient. Instead, we can use the plot in Figure 4 to get a sense of the relationship in the full data. ${ }^{11}$ Visual inspection suggests that Statutory Control increases only slightly with State Court Index until it reaches a threshold near 10 on the $\mathrm{x}$-axis. The dependent variable then rises logarithmically until State Court Index hits another threshold at 22, at which point, Statutory Control decreases until it levels off at 1,000 added words. This plot displays strong evidence of nonlinearity, at least in the bivariate relationship.

Recall that the explicit prediction of the theoretical model was that nonstatutory factors should have this nonlinear effect on the delegation of discretion only when there is sufficient policy conflict

\footnotetext{
${ }^{11}$ As there is no way to control for outliers in a bivariate framework, I omit California from the lowess results.
} 
between the legislature and agency (Region 3). Figure 5 displays the lowess estimates for different levels of policy conflict. The figure on the left plots the clearly nonlinear relationship for the data from states with divided government in $1995 .^{12}$ Since party control is the only measure of policy conflict I have, I consider divided government to indicate that the conflict is sufficiently large to sustain the prediction regarding nonstatutory controls. The plot on the right allows us to assess the extent to which this relationship may differ when there is less policy conflict. We see here, contrary to expectations, that the same relationship holds when there is unified government or a divided legislature. Although this diagnostic does not support the hypothesis regarding policy conflict, the plots presented here indicate a strong and consistent nonlinear relationship between the main variables, indicating that semiparametric regression is an appropriate modeling choice.

Local smoothing techniques such as local regression and spline smoothing are useful for diagnoses of nonlinearity, but since they can only summarize bivariate relationships they are not very useful for modeling social science data (Keele, 2008, p. 109). Fortunately, these techniques can be incorporated quite easily into the standard parametric regression framework. Below, I estimate a standard parametric model of the determinants of Statutory Control and compare it to a Generalized Additive Model (GAM) which estimates a smoothed functional form for State Court Index while simultaneously estimating the remaining variables parametrically.

The model in the first column of Table 2 presents the results for a parametric Poisson model of the determinants of Statutory Control across the states. ${ }^{13}$ These results can be contrasted with those from Huber, Shipan and Pfahler (2001) and Huber and Shipan (2002). ${ }^{14}$ In what is essentially the same specification otherwise, inclusion of the State Court Index variable leads to the divided government variables and interactions either losing their significance or switching direction. Although

\footnotetext{
${ }^{12}$ Divided government is considered to be when a state governor's party controls neither legislative chamber, i.e., when UnifiedLegislature $=1$ or when DividedLegislature $=1$. The non-divided government plot includes states where UnifiedLegislature $=0$ and DividedLegislature $=0$.

${ }^{13} \mathrm{I}$ also specified parametric OLS and negative binomial regression models, but the results were nearly identical across parametric specifications.

${ }^{14}$ Huber, Shipan and Pfahler (2001) and Huber and Shipan (2002) hold that policy conflict (unified legislature), legislative capacity (compensation), bargaining environment (divided legislature), and nonstatutory factors (legislative veto) should all have linear effects on statutory control. In contrast, my model predicts that only what they term nonstatutory factors, modified by policy conflict, should systematically vary with statutory control.
} 
it is highly statistically significant, the substantive effect of the $\gamma$ variable seems quite small. If we believed that the relationship between State Court Index and Statutory Control was linear, we would create a plot of how increases in the independent variable would lead to, since the coefficient is negative, decreases in expected levels of Statutory Control. Such a conclusion would be consistent with the Huber and Shipan model of discretion, which predicts a standard linear substitutive relationship between ex post capacity and ex ante control, but inconsistent with my model.

The second column of this table presents results from a semiparametric GAM model with the same independent variables. Essentially, the GAM framework allows one to simultaneously estimate a smoothing spline for nonlinear terms and conventional parameters for linear ones. ${ }^{15}$ The first important thing to notice is that this model fits the data significantly better than the parametric model (likelihood-ratio test $p<.001$ ). Given what we know about the nonlinearity in State Court Index from Figures 4 and 5, this is not surprising. In addition to providing an overall better fit, the Poisson GAM leads to reinterpretations of the effects of some of the parametric terms. For example, the constitutive Unified Legislature term switches signs and gains a high level of statistical significance, while its interaction with Compensation does the same.

Since the Poisson GAM estimates a spline for the effect of State Court Index on Statutory Control, we cannot summarize the relationship with a coefficient and standard error. Instead, the standard way to interpret nonparametric terms in GAMs is to inspect a plot of their effects across the range. In the interest of presenting substantively meaningful results rather than difficult to interpret propensities from the Poisson GAM, I have plotted the effects of the nonparametric term from a semiparametric OLS regression in Figure 6. This plot confirms that the relationship, even while controlling for the other independent variables in the model, between $\gamma$ and thousands of words is obviously nonlinear. Contrary to the parametric model, which told us that the effect was significantly negative, this plot shows that the direction of the effect varies across the range of State Court Index. The shape of the nonlinearity displayed here is broadly consistent with the ex-

\footnotetext{
${ }^{15}$ Keele (2008)(pp. 140-141) describes some estimation procedures for GAMs and notes that different software may estimate these models differently. I have used the mgCv package in $\mathrm{R}$ to estimate the poisson GAM below. This package uses iterated reweighted least squares to estimate GAMs.
} 
pectations of the theory. In particular, we see that the effect of the State Court Index significantly increases Statutory Control in the range from around 11 to 15, until it begins reverting to a zero, or insignificantly (given the coverage of 0 by the confidence bands) negative effect. Lest we worry that this significant hump in the effect is produced by a lack of data or outliers, Figure 5 tells us that there are a great many data points across the range of Statutory Control in the 11 to 20 range of the $\mathrm{x}$-axis, where the effect is statistically distinguishable from zero. It is important to note that the theory holds that this should only be the case when there is sufficient policy conflict. Since the models to which I am comparing my approach contain variables that capture policy conflict (Unified Legislature and Divided Legislature), it is difficult to discern if the nonlinear relationship holds only divided government, or if policy convict serves to mediate the effects of State Court Index at all. Given that I am relying on semiparametric modeling techniques, interaction effects are difficult to model, save for splitting the sample - a route I did not take here given the relatively small sample sizes. A potential strategy to assess the effects of policy conflict might be to pool these data with those from a different policy area or time period, a process which I partially describe in the next section.

\section{Discussion}

This research has contributed to the study of state-level executive-legislative relations in a number of ways. First, it approaches questions of delegation and oversight with a general theoretical framework that generates novel predictions about the relationship between nonstatutory controls and the incentive to write statutory controls into legislation. In so doing, the model summarized here extends and generalizes the influential Huber and Shipan (2002) model of delegation, while providing starkly differing empirical expectations as described through this paper. The approach here and the contributions it allows follows the spirit of Krause and Woods's (2012) call to take seriously difference in institutional capacity that permeate state politics in developing theories of bureaucratic politics ate the subnational level. 
In addition, I test the implications of this analytical model on statutory discretion across the U.S. states in the Medicaid policy area in 1995-1996. I replicate and modify the empirical analyses found in Huber, Shipan and Pfahler (2001) and Huber and Shipan (2002) by creating a novel measure of state court activism as a nonstatutory control across the states. I demonstrate that this variable is, as expected, nonlinearly related to statutory control and I appropriately model the empirical relationship nonparametrically. Interestingly, when we analyze the same data used in these studies in light of the predictions generated from the model presented here, I contend that we see strong evidence of nonlinearity of effects. If we were to naïvely test these predictions using a linear framework, we would instead find support for the linear predictions of Huber, Shipan and Pfahler (2001) and Huber and Shipan (2002). While the general results suggest support for the hypothesis that nonstatutory factors should increase statutory discretion when they are neither too high nor too low, there is very limited support for the conditional hypothesis that this should only be the case when there is sufficient policy conflict between a legislature and an agency.

As noted above, MacDonald and Franko (2007) do not use the length of legislative statutes as a measure of statutory control over bureaucratic discretion. Instead, they look at the use of limitation riders in appropriations bills as indicative of proscribed delegation. In addition, motivated by the theoretical work on procedural constraints (McCubbins and Schwartz, 1984; McCubbins, Noll and Weingast, 1987, 1989; Moe, 1990), Epstein and O’Halloran (1999) measure policymaking autonomy by identifying, through Congressional Quarterly reports, the extent to which statutes both delegate policy authority and set procedural limits on that authority. While this would no doubt be an innovative complement to the data on statutory discretion used in Huber and Shipan (2002) and in the current paper, it would be impossible to collect at the state level, since there is no uniform state-level equivalent to Congressional Quarterly. Besides, Huber and Shipan (2002, pp. 56-72) go through pains to highlight the importance of prescriptive language, and not procedural language, in these state Medicaid statutes. ${ }^{16}$ Had they not, there would be much more reason to

\footnotetext{
${ }^{16}$ As well as they show that “... longer legislation does not consist of mostly general language ... [and] that longer legislation does not contain proportionally more procedural language” (Huber and Shipan, 2002, p.74).
} 
suspect that statute length may not be a good proxy for delegation of discretion. Therefore, to the extent that future research delves into new policy areas, we must be keen to diagnose the extent to which legislation in those areas rely on relatively brief, yet highly restrictive, procedural language. Among many directions for future research, I am now following a few especially important ones. As I have assessed the theoretical model's predictions regarding ex ante discretion in this paper, I have previously shown support for the ex post oversight hypotheses at the congressional level (McGrath, 2011). However, a more stringent test of the theory would require me to collect data on ex ante discretion in a policy area along with ex post monitoring activities in the same area and assess the theoretical expectations simultaneously. I have collected the data on statutory control in state legislation meant to implement mandates from the federal "No Child Left Behind" (Public Law 107-110) act, but still need supplement these data with information on state court activism for this later period. In addition to the ex ante legislation, I am collecting myriad data related to ex post monitoring of state departments of educations by legislative committees across the U.S. states. Specifically related to the limitation of the policy conflict measure in this study, I am taking care to code the ideology of committee members as well as that of agency decionmakers. Also, while explaining executive-legislative relations and legislative strategies of control are important topics in themselves, future work should integrate this research with policy studies to assess whether control has discernible effects on policy outcomes (Krause and Woods, 2012). 


\section{References}

Aranson, Peter, Ernest Gellhorn and Glen Robinson. 1982. "A Theory of Legislative Delegation.” Cornell Law Review 68:55-63.

Balla, Steven J. 1998. "Administrative Procedures and Political Control of the Bureaucracy.” The American Political Science Review 92(3):663-673.

Bawn, Kathleen. 1995. "Political Control Versus Expertise: Congressional Choices about Administrative Procedures." The American Political Science Review 89(1):62-73.

Bawn, Kathleen. 1997. "Choosing Strategies to Control the Bureaucracy: Statutory Constraints, Oversight, and the Committee System.” Journal of Law, Economics, \& Organization 13(1):101126.

Berman, David R. 2004. Effects of Legislative Term Limits in Arizona. Final Report for the Joint Project on Term Limits.

URL: http://www.ncsl.org/jptI/casestudies/CaseContents.htm

Bonfield, Arthur Earl. 1986. State Administrative Rule Making. Boston: Little, Brown.

Brace, Paul, Laura Langer and Melinda Gann Hall. 2000. "Measuring the Preferences of State Supreme Court Judges.” The Journal of Politics 62(2):387-413.

Carey, John M., Richard G. Niemi and Lynda Powell. 2000. Term Limits in the State Legislatures. Ann Arbor: University of Michigan Press.

Carey, John M., Richard G. Niemi, Lynda W. Powell and Gary Moncrief. 2006. "The Effects of Term Limits on State Legislatures: Results from a New Survey of the 50 States." Legislative Studies Quarterly 30:105-34. 
Carpenter, Daniel P. 2000. Stochastic Prediction and Estimation of Nonlinear Political Durations: An Application to the Lifetime of Bureaus. In Political Complexity: Nonlinear Models of Politics, ed. Diana Richards. University of Michigan Press pp. 209-238.

Carpenter, Daniel P. 2001. The Forging of Bureaucratic Autonomy: Reputations, Networks, and Policy Innovation in Executive Agencies. Princeton: Princeton University Press.

Carpenter, Daniel P. 2010. Reputation and Power: Organizational Image and Pharmaceutical Regulation at the FDA. Princeton, NJ: Princeton University Press.

Carpenter, Daniel P. and David E. Lewis. 2004. "Political Learning from Rare Events: Poisson Inference, Fiscal Constraints, and the Lifetime of Bureaus." Political Analysis 12:201-232.

Davis, Kenneth Culp. 1978. Administrative Law Treatise. Vol. i San Diego, CA: Davis KC.

de Figueiredo Jr., Rui J. P., Tonja Jacobi and Barry R. Weingast. 2008. The New Separationof-Powers Approach to American Politics. In The Oxford Handbook of Political Economy, ed. Barry R. Weingast and Donald Wittman. Oxford University Press.

Elling, Richard C. 1979. "The Utility of State Legislative Casework as a Means of Oversight." Legislative Studies Quarterly 4:353-379.

Epstein, David and Sharyn O’Halloran. 1994. “Administrative Procedures, Information, and Agency Discretion.” American Journal of Political Science 38(3):697-722.

Epstein, David and Sharyn O'Halloran. 1996. "Divided Government and the Design of Administrative Procedures: A Formal Model and Empirical Test." The Journal of Politics 58(2):373-397.

Epstein, David and Sharyn O'Halloran. 1999. Delegating Powers: A Transaction Cost Politics Approach to Policymaking Under Separate Powers. Cambridge: Cambridge University Press.

Erikson, Robert S., Gerald C. Wright and John P. McIver. 1993. Statehouse Democracy: Public Opinion and Policy in the American States. Cambridge: Cambridge University Press. 
Farmer, Rick and Thomas H. Little. 2004. Legislative Power in the Buckeye State: The Revenge of Term Limits. Final Report for the Joint Project on Term Limits.

URL: http://www.ncsl.org/jptl/casestudies/CaseContents.htm

Gailmard, Sean. 2002. "Experise, Subversion, and Bureaucratic Discretion.” Journal of Law, Economics, \& Organization 18(2):536-555.

Garner, Bryan A. 2006. Black’s Law Dictionary. West Publishing Company.

Gellhorn, Walter. 1986. “The Administrative Procedure Act: The Beginnings." Virginia Law Review 72(2):219-233.

Hamilton, James T. and Christopher H. Schroeder. 1994. "Strategic Regulators and the Choice of Rulemaking Procedures: The Selection of Formal vs. Informal Rules in Regulating Hazardous Waste." Law and Contemporary Problems 57(2):111-160.

Hamm, Keith E. and Roby D. Robertson. 1981. "Factors Influencing the Adoption of New Methods of Legislative Oversight in the U.S. States.” Legislative Studies Quarterly 6(1):133-150.

Huber, Gregory A. 2007. The Craft of Bureaucratic Neutrality: Interests and Influence in Governmental Regulation of Occupational Safety. New York, NY: Cambridge University Press.

Huber, John D. and Charles R. Shipan. 2002. Deliberate Discretion? The Institutional Foundations of Bureaucratic Autonomy. Cambridge: Cambridge University Press.

Huber, John D., Charles R. Shipan and Madelaine Pfahler. 2001. "Legislatures and Statutory Control of Bureaucracy." American Journal of Political Science 45(2):330-345.

Keele, Luke. 2008. Semiparametric Regression for the Social Sciences. London: Wiley and Sons.

Kim, Jenseok and Brian J. Gerber. 2005. "Bureaucratic Leverage over Policy Choice: Explaining the Dynamics of State-Level Reforms in Telecommunications Regulation.” Policy Studies Journal 33(4):613-634. 
Kousser, Thad. 2005. Term Limits and the Dismantling of State Legislative Professionalism. Cambridge: Cambridge University Press.

Krause, George A. and Neal D. Woods. 2012. "Policy Delegation, Comparative Institutional Capacity, and Administrative Politics in the American States”. In Oxford Handbook of State and Local Government, ed. Donald P. Haider-Markel. New York, NY: Oxford University Press.

Kurtz, Karl T., Bruce Cain and Richard G. Niemi, eds. 2007. Institutional Change in American Politics: The Case of Term Limits. Ann Arbor, MI: University of Michigan Press.

Lewis, David E. 2003. Presidents and the Politics of Agency Design: Political Insulation in the United States Government Bureaucracy. Stanford: Stanford University Press.

Lowi, Theodore. 1969. The End of Liberalism: The Second Republic of the United States. New York: W.W. Norton.

MacDonald, Jason A. 2010. "Limitation Riders and Congressional Influence over Bureaucratic Policy Decisions." American Political Science Review 104(4):766-782.

MacDonald, Jason A. and William W. Franko. 2007. "Bureaucratic Capacity and Bureaucratic Discretion: Does Congress Tie Policy Authority to Performance?" American Politics Research $35: 790$.

McConnell, Grant. 1966. Private Power and American Democracy. New York: Vintage Books.

McCubbins, Mathew D., Roger G. Noll and Barry R. Weingast. 1987. “Administrative Procedures as Instruments of Political Control.” Journal of Law, Economics, \& Organization 3(2):243-277.

McCubbins, Mathew D., Roger G. Noll and Barry R. Weingast. 1989. "Structure and Process, Politics and Policy: Administrative Arrangements and the Political Control of Agencies." Virginia Law Review 75:431-482. 
McCubbins, Mathew D. and Thomas Schwartz. 1984. "Congressional Oversight Overlooked: Police Patrols versus Fire Alarms.” American Journal of Political Science 28(1):165-179.

McGrath, Robert J. 2010. "Explaining Congressional Oversight as an Ex Post Control Mechanism”. Paper presented at the 2010 meeting of the Midwest Political Science Association, April 24, Chicago, IL.

McGrath, Robert J. 2011. "Strategic Oversight and the Institutional Determinants of Legislative Policy Control” PhD thesis University of Iowa Iowa City, IA: .

Moe, Terry M. 1990. The Politics of Structural Choice: Toward a Theory of Public Bureaucracy. In Organization Theory: From Chester Barnard to the Present and Beyond, ed. Oliver E. Williamson. New York: Oxford University Press pp. 116-153.

Niskanen, William. 1971. Bureaucracy and Representative Government. Chicago: AldineAtherton.

O’Connor, J. 1978. “The Democratic Movement in the United States.” Kapitalistate 7:15-26.

Offe, C. 1972. "Political Authority and Class Structures: An Analysis of Late Capitalist Societies." International Journal of Sociology 2:73-108.

Peters, B. Guy. 1981. "The Problem of Bureaucratic Government.” Journal of Politics 43:56-82.

Poggione, Sarah and Christopher Reenock. 2009. "Political Insulation and Legislative Interventions: The Impact of Rule Review." State Politics and Policy Quarterly 9:456-485.

Potoski, Matthew. 1999. "Managing Uncertainty through Bureaucratic Design: Administrative Procedures and State Air Pollution Control Agencies." Journal of Public Administration Research and Theory 9:623-639. 
Potoski, Matthew and Neal D. Woods. 2000. "Designing State Clean Air Agencies: Administrative Procedures and Bureaucratic Autonomy." Journal of Public Administration Research and Theory 11:203-21.

Putnam, Robert D. 1975. The Political Attitudes of Senior Civil Servants in Britain, Germany, and Italy. In The Mandarins of Western Europe, ed. Mattei Dogan. New York: Sage Publications pp. 87-127.

Rourke, Francis E. 1984. Bureaucracy, Politics, and Public Policy. 3rd ed. Boston: Little, Brown.

Sarbaugh-Thompson, Marjorie, Kelly Leroux, Richard C. Elling, Lyke Thompson and Charles D. Elder. 2010. "Legislators and Administrators: Complex Relationships Complicated by Term Limits." Legislative Studies Quarterly 35:57.

Shapiro, Martin M. 1982. Who Guards the Guardians? Athens, GA: University of Georgia Press.

Teske, Paul. 2004. Regulation in the States. Washington, DC: Brookings Institution Press.

Wood, B. Dan and John Bohte. 2004. "Political Transaction Costs and the Politics of Administrative Design." Journal of Politics 66:176-202.

Woods, Neal D. and Michael Baranowski. 2006. "Legislative Professionalism and Influence on State Agencies: The Effects of Resources and Careerism." Legislative Studies Quarterly 31:585609. 
Table 1: Descriptive Statistics

\begin{tabular}{lccccc}
\hline \hline & & & & & \\
& count & mean & sd & min & max \\
\hline Total added words, 1995-96 & 48 & 24683.3 & 44344.7 & 216 & 277495 \\
Average State Supreme Court Ideology & 48 & 44.8 & 15.3 & 14.8 & 82.2 \\
Proportion of Overturned Agency Decisions & 48 & 0.34 & 0.12 & 0.068 & 0.58 \\
State Court Index & 48 & 15.3 & 7.94 & 2.92 & 44.3 \\
$\ln ($ Compensation) & 48 & 9.21 & 1.83 & 0 & 11.0 \\
Unified Legislature & 48 & 0.31 & 0.47 & 0 & 1 \\
Divided Legislature & 48 & 0.19 & 0.39 & 0 & 1 \\
Legislative Veto & 48 & 0.60 & 0.49 & 0 & 1 \\
Medicaid Expenditures & 48 & 0.57 & 0.18 & 0.34 & 1.33 \\
\hline \hline
\end{tabular}


Table 2: Parametric and Semiparametric Models of Statutory Control (in thousands of words added) Across U.S. States, 1995-1996

\begin{tabular}{|c|c|c|}
\hline & Poisson & Poisson GAM \\
\hline \multirow[t]{2}{*}{ In(Compensation) } & $.39 * * *$ & $.64 * * *$ \\
\hline & .05 & .08 \\
\hline \multirow[t]{2}{*}{ Unified Legislature } & -.64 & $4.91 * * *$ \\
\hline & .88 & 1.39 \\
\hline \multirow[t]{2}{*}{ Unified Legislature $* \ln ($ Compensation $)$} & .09 & $-.49 * * *$ \\
\hline & .09 & .09 \\
\hline \multirow{2}{*}{ Divided Legislature } & $5.77 * *$ & $9.79 * * *$ \\
\hline & 1.86 & 2.84 \\
\hline \multirow{2}{*}{ Divided Legislature $* \ln ($ Compensation $)$} & $-.65 * * *$ & $-1.03 * * *$ \\
\hline & .19 & .28 \\
\hline \multirow[t]{2}{*}{ Legislative Veto } & $-.37 * * *$ & $-.42 * * *$ \\
\hline & .09 & .11 \\
\hline \multirow{2}{*}{ Legislative Veto * Unified Legislature } & $-.42 *$ & $-1.15 * * *$ \\
\hline & .20 & .28 \\
\hline \multirow[t]{2}{*}{ Medicaid Expenditures } & $2.04 * * *$ & .61 \\
\hline & .25 & .41 \\
\hline \multirow[t]{2}{*}{ South } & $-.68 * * *$ & $-1.15 * * *$ \\
\hline & .12 & .19 \\
\hline \multirow[t]{2}{*}{ California } & $3.10 * * *$ & $2.67 * * *$ \\
\hline & .20 & .34 \\
\hline \multirow[t]{2}{*}{ State Court Index $(\gamma)$} & $-.03 * * *$ & —*** \\
\hline & .004 & \\
\hline \multirow[t]{2}{*}{ Constant } & $-1.02 *$ & $-4.79 * * *$ \\
\hline & .48 & .96 \\
\hline Observations & 48 & 48 \\
\hline Deviance Explained & $59 \%$ & $83 \%$ \\
\hline LR test $p$-value & & .00 \\
\hline
\end{tabular}

Likelihood ratio test against previous model in the table.

Standard errors in parentheses.

* significant at $10 \%$; ** significant at 5\%; *** significant at $1 \%$ 
Figure 1: Region 1 - Separating Equilibrium

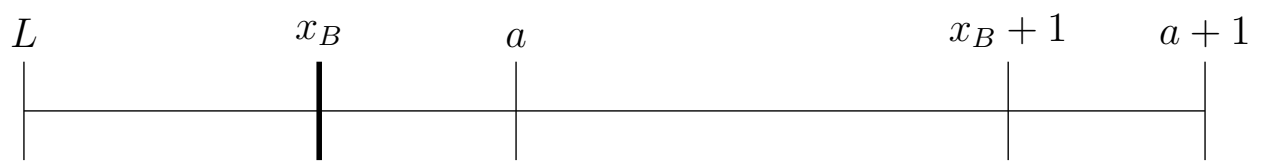

Separating Equilibrium: $x_{B}<a$

- L passes $x=x_{B}+1$, B implements $y_{1}=x_{B}+1$ when $\epsilon=1, \mathrm{~L}$ does not investigate

- L passes $x=x_{B}+1$, B implements $y_{0}=x_{B}$ when $\epsilon=0, \mathrm{~L}$ does not investigate

Figure 2: Region 2 - Separating Equilibrium

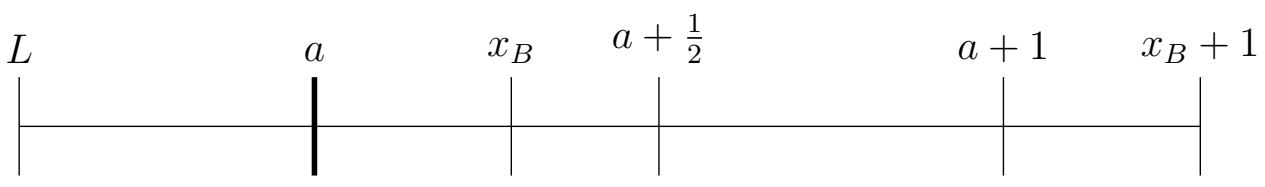

Separating Equilibrium: $a \leq x_{B} \leq a+\frac{1}{2}$

- L passes $x=x_{B}+1$, B implements $y_{1}=a+1$ when $\epsilon=1$, $\mathrm{L}$ does not investigate

- L passes $x=x_{B}+1$, B implements $y_{0}=a$ when $\epsilon=0, \mathrm{~L}$ does not investigate

Figure 3: Region 3 - Semi-separating Equilibrium

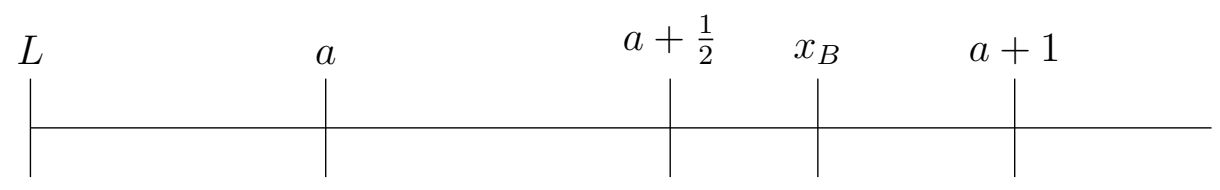

Semi-separating: $a+\frac{1}{2}<x_{B}$

- There is no pure separating strategy for B here

- If $\epsilon=1$, B plays pure $a+1$

- If $\epsilon=0, \mathrm{~B}$ mixes between $a+1$ and $a$ 
Figure 4: Lowess Smoother, No California

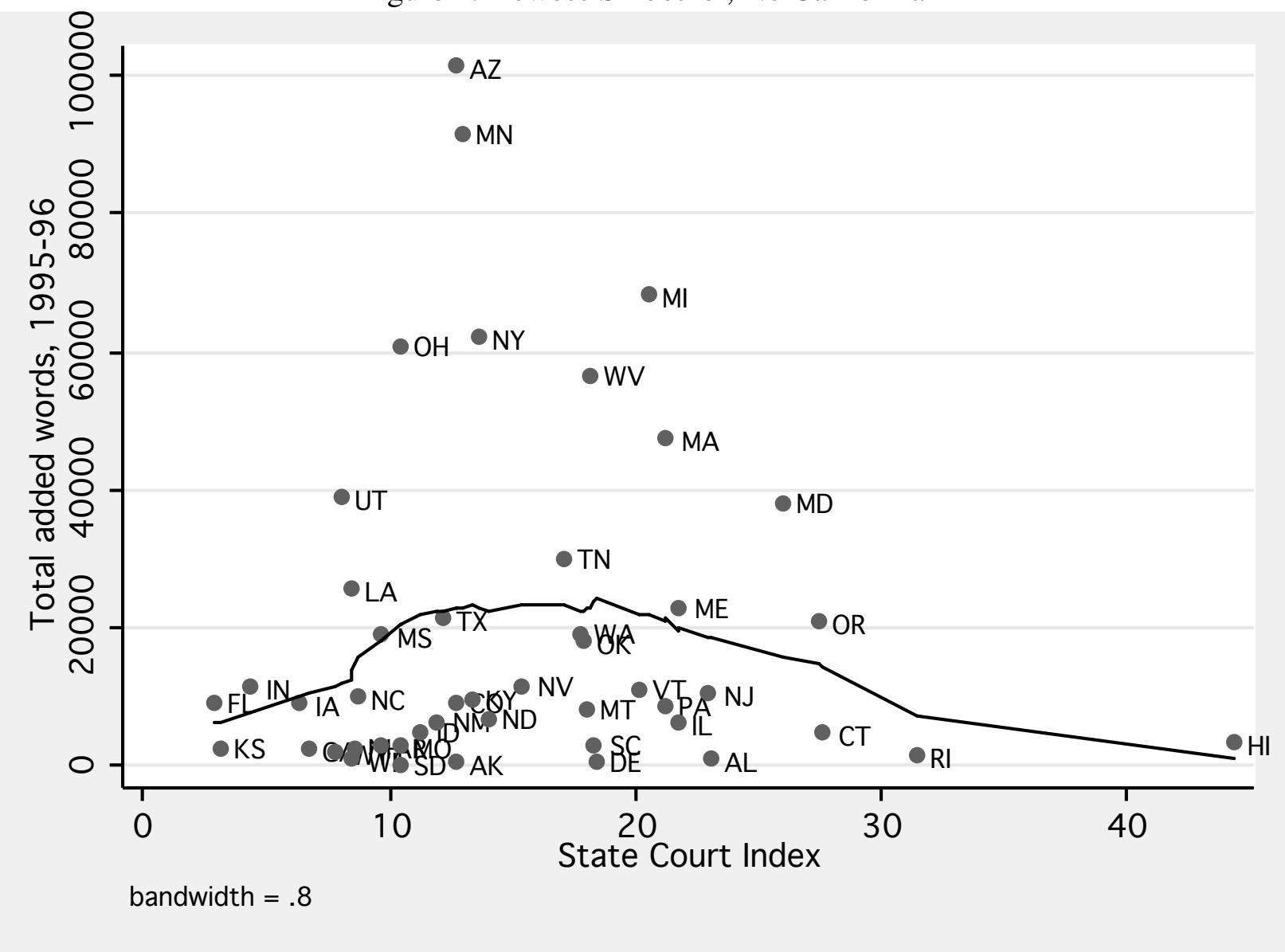


Figure 5: Lowess Smoother, No California
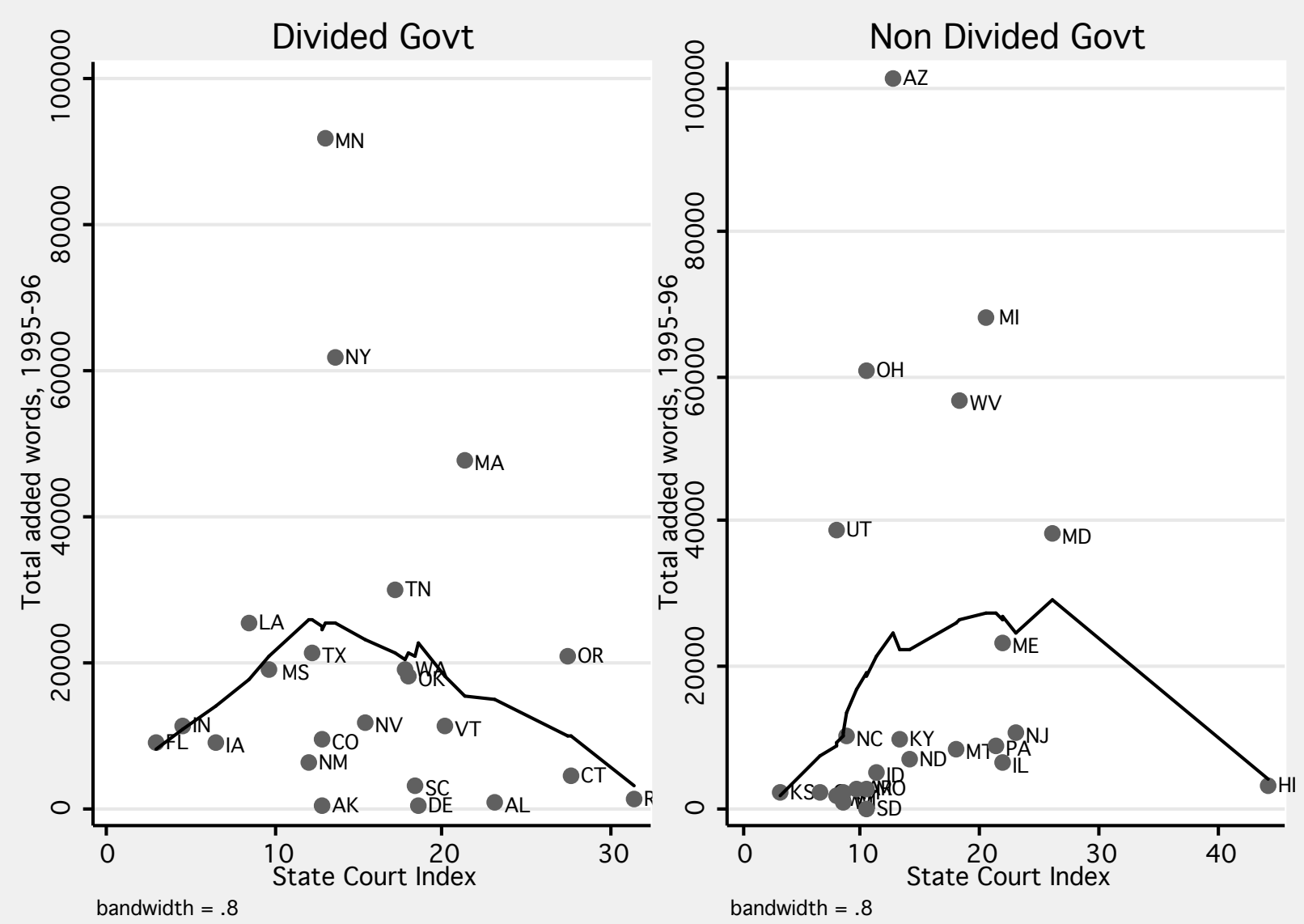
Figure 6: Nonparametric Estimates from Semiparametric OLS Regression Model

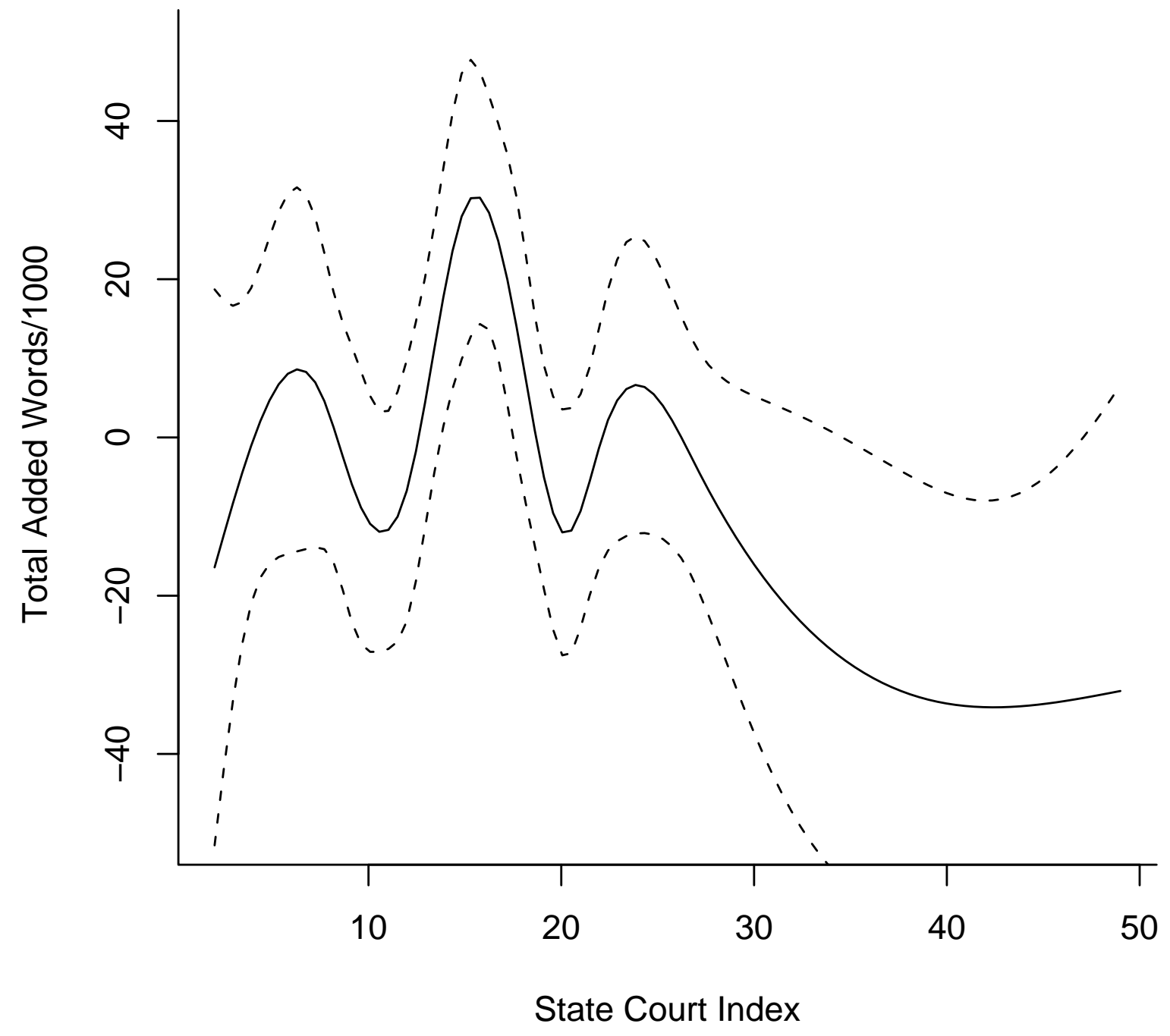

